\title{
Local buckling strength of steel foam sandwich panels
}

\author{
S Szyniszewski $^{\mathrm{a} 1}$, BH Smith $^{\mathrm{b}}$, JF Hajjar $^{\mathrm{c}}, \mathrm{SR}$ Arwade $^{\mathrm{b}}, \mathrm{BW}$ Schafer $^{\mathrm{a}}$ \\ ${ }^{a}$ Dept. of Civil Eng., Johns Hopkins University, Baltimore, MD 21218 \\ ${ }^{\mathrm{b}}$ Dept. of Civil and Env. Eng., University of Massachusetts, Amherst, MA 01003 \\ ${ }^{c}$ Dept. of Civil and Env. Eng., Northeastern University, Boston, MA 02115
}

\begin{abstract}
The objective of this paper is to provide and verify a new design method for the in-plane compressive strength of steel sandwich panels comprised of steel face sheets and foamed steel cores. Foamed steel, literally steel with internal voids, provides enhanced bending rigidity, exceptional energy dissipation, and the potential to mitigate local instability. In this work, Winter's effective width expression is generalized to the case of steel foam sandwich panels. The generalization requires modification of the elastic buckling expressions to account for panel non-composite bending rigidity and shear deformations. In addition, an equivalent yield stress is introduced to provide a single parameter description of the yielding behavior of the steel face sheets and steel foam core. The provided analytical expressions are verified with finite element simulations employing three-dimensional continuum elements and calibrated constitutive models specific to metallic foams. The developed closed-form design expressions are employed to conduct parametric studies of steel foam sandwich panels, which (a) demonstrate the significant strength improvements possible when compared with solid steel, and (b) provide insights on the optimal balance between steel face sheet thickness and density of the foamed steel core. This work is part of a larger effort to help develop steel foam as a material with relevance to civil engineering applications.
\end{abstract}

Keywords: steel foam, metal foam, sandwich panels, composite panels, local buckling, instability, compressive strength

\footnotetext{
${ }^{1}$ Corresponding author: 203 Latrobe Hall, 3400 Charles St, Baltimore, MD 21218

s.szyniszewski@gmail.com | sszynis1@jhu.edu
} 


\section{Introduction}

Foamed steel intentionally introduces internal voids in steel, e.g. Figure 1. A variety of manufacturing methods are used to introduce the voids from powder metallurgy and sintering of hollow spheres to gasification [2]. Steel foams are largely still under development, e.g. [7]; however steel foam sandwich panels have been utilized in a demonstration project as a parking garage slab [8]. Mass production of aluminum foam sandwich panels (Figure 2, [3]) as well as successful aluminum foam sandwich panel applications in aerospace [3], automotive [4],[5], and manufacturing [9] demonstrate the basic potential. In general, metal foams have high effective bending stiffness and energy absorption. In addition, metal foams have improved thermal conductivity [9], enhanced fire resistance [10],[11], better noise attenuation [2],[6], and provide improved electromagnetic and radiation shielding [12],[13] when compared with solid metals.
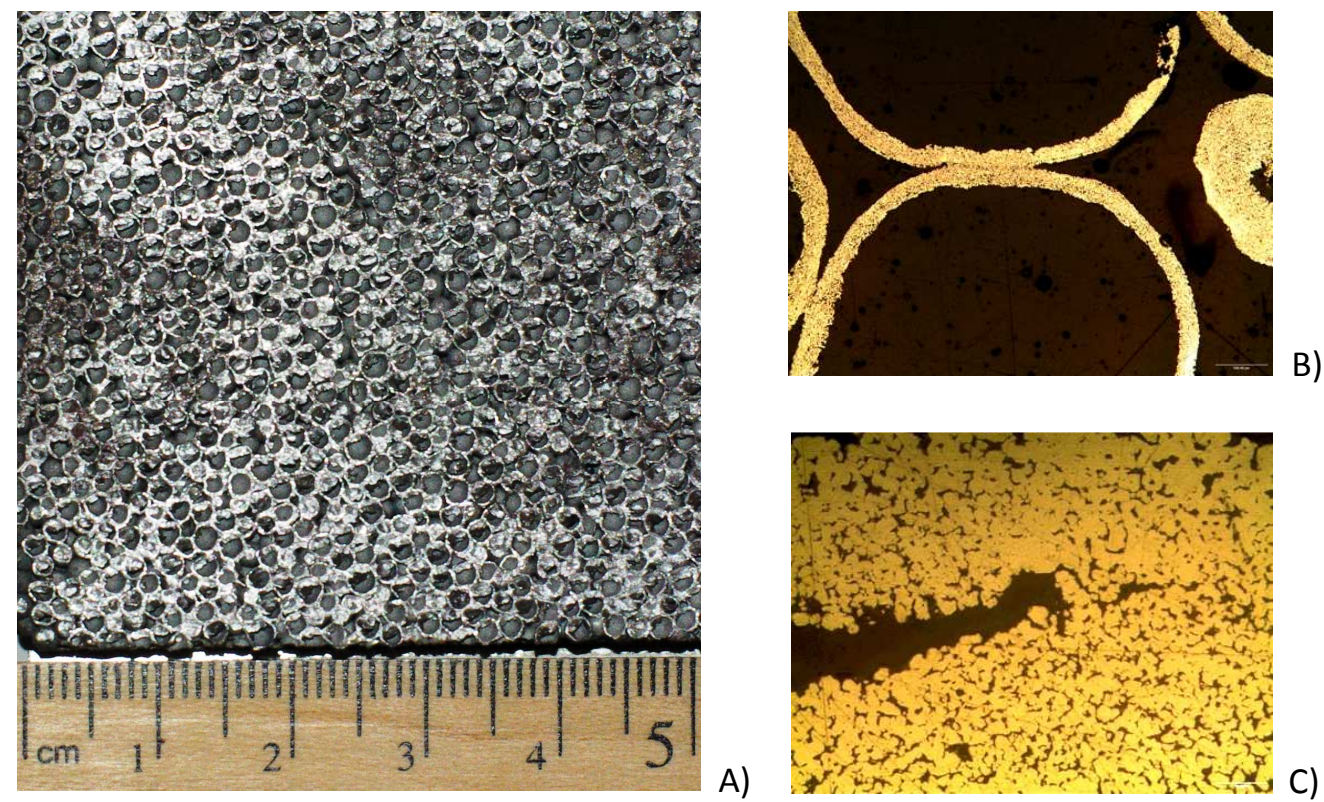

B)

A)

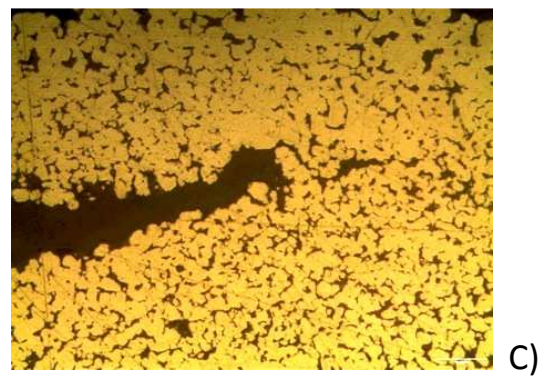

Figure 1. Steel hollow sphere foam $18 \%$ relative density: A) interior foam morphology through cut section, B) contact between spheres as shown in cross-section, C) sphere walls are not fully dense. 


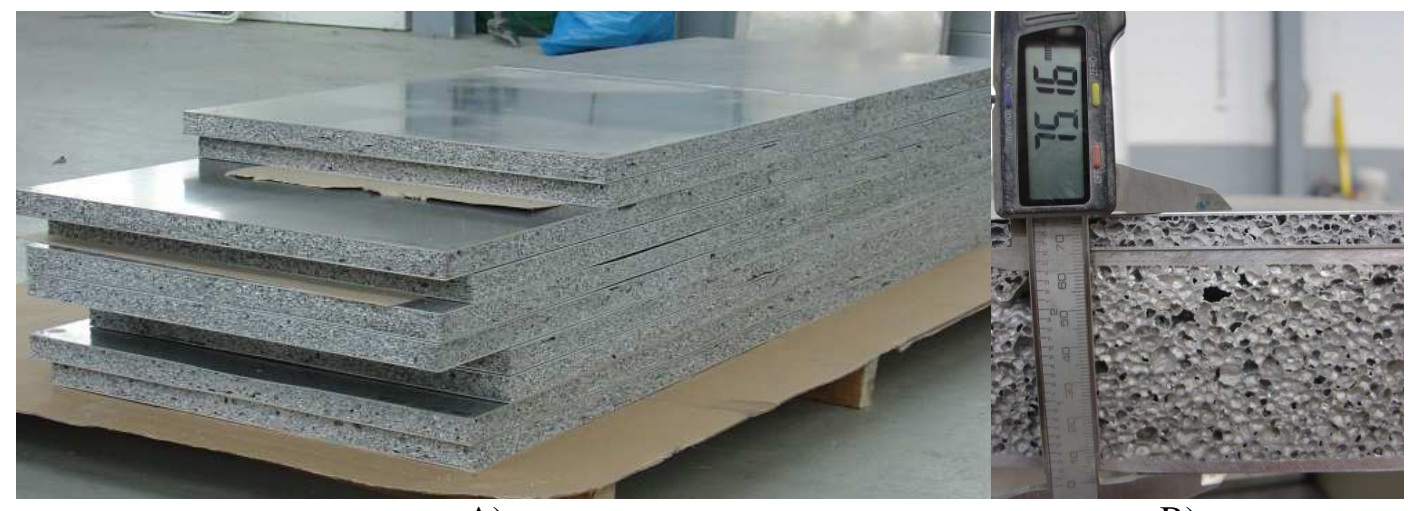

A)

B)

Figure 2. Aluminum foam sandwich panels a) on pallet, b) in section [3]. (Photo credit: J Banhart)

The overall objective of this study is to develop a design method for the determination of the inplane compressive strength of steel foam sandwich panels comprised of solid steel face sheets and foamed steel cores. The design method development requires: (a) determination of the effective bending rigidity, including shear deformations, and the resulting local buckling stress, (b) determination of the yield strength for the composite (solid and foamed steel) panel, and (c) application and verification/calibration of Winter's effective width expression (originally from [1]) suitably modified by (a) and (b). Validation of the developed bending rigidity and design expressions is provided through continuum finite element solutions of steel foam sandwich panels.

\section{Basic steel foam material properties}

\subsection{Uniaxial stress-strain behavior}

A typical compressive stress-strain curve for the steel foam of Figure 1 is provided in Figure 3 . This commercially available steel foam, manufactured by the Fraunhofer Institute in Germany, employs sintered hollow steel spheres and has a relative density $\rho=0.18$. The authors are involved in a wider experimental program for complete materials characterization of this foam. For a typical sample the initial compression modulus, $E_{f c}$ is approximately $450 \mathrm{MPa}$, the yield stress in compression $f_{y f}$ is approximately $6 \mathrm{MPa}$, and the compressive strain before the onset of densification of the steel foam 
walls is nearly $100 \%$. In tension the initial modulus and yield stress are similar but tensile strain capacity is only on the order of $2 \%$. These properties are utilized throughout this paper as representative of an available low density steel foam.

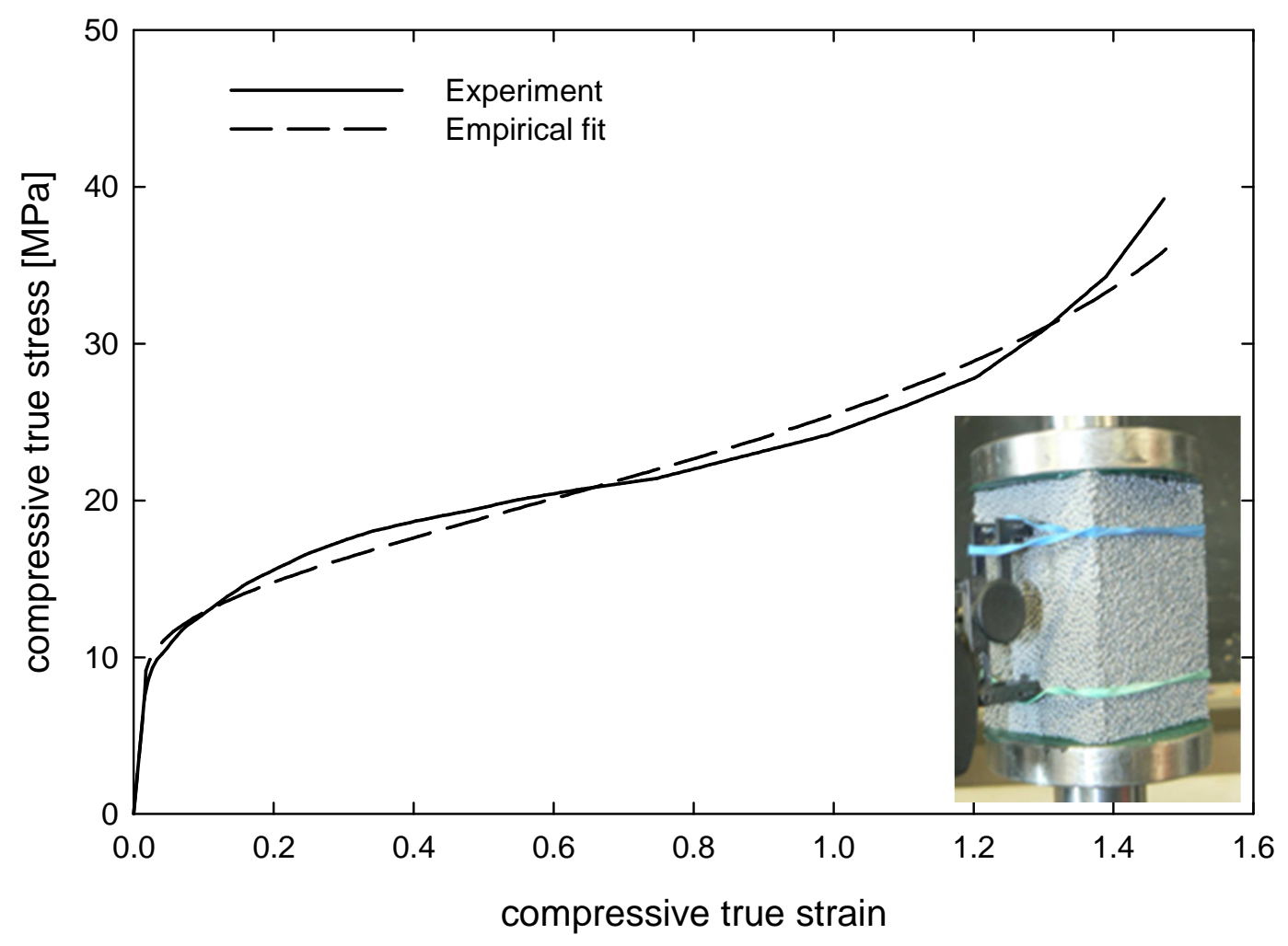

Figure 3. Uniaxial compression test for calibration of D-F plasticity

\subsection{Plate bending rigidity and local plate buckling stress}

The bending rigidity of a steel foam plate exceeds that of a solid plate. This is not immediately obvious when one considers that the foaming process itself decreases the apparent modulus. Consider a plate with initial thickness $t_{i n i}$, if the entire plate is foamed, the thickness $t_{f}$ is:

$$
t_{f}=t_{\text {ini }} / \rho
$$

where $\rho$ is the relative density of the foamed steel ( $\rho=1$ is a solid steel plate). Based on the work of [2] the foamed steel modulus, $E_{f}$ is related to the solid steel modulus, $E_{s}$, by: 


$$
E_{f} \propto E_{s} \rho^{2}
$$

Substituting these relations into the standard expression for plate bending rigidity (and assuming no change in Poisson's ratio, $v$, for the foamed steel):

$$
D_{f}=\frac{E_{f} t_{f}^{3}}{12\left(1-v^{2}\right)} \propto \frac{\left(E \rho^{2}\right)\left(t_{i n i} / \rho\right)^{3}}{12\left(1-v^{2}\right)} \propto \frac{1}{\rho} \frac{E t_{i n i}{ }^{3}}{12\left(1-v^{2}\right)} \propto \frac{1}{\rho} D_{\text {solid }}
$$

Thus, by virtue of the strong role that thickness plays in plate bending rigidity, a foamed steel plate has a higher plate bending rigidity than a solid plate.

If instead of foaming the entire plate, only a central fraction of the core, $\alpha(0 \leq \alpha \leq 1)$ is foamed, thus creating an all steel sandwich panel, the increase in plate bending rigidity can be even more pronounced. Assuming now the relative density, $\rho$, applies only to the foamed core, then the core thickness, $t_{c}$, increased from the initial solid plate thickness $t_{i n i}$, is:

$$
t_{c}=\frac{\alpha t_{\text {ini }}}{\rho}
$$

The remaining portion of the initial solid sheet is split evenly between two face sheets of thickness, $t_{s}$ :

$$
t_{s}=\frac{1-\alpha}{2} t_{\text {ini }}
$$

The plate bending rigidity, again assuming constant $v$, is:

$$
D_{p}=\frac{E_{s}\left(t_{c}+2 t_{s}\right)^{3}-\left(E_{s}-E_{f}\right) t_{c}{ }^{3}}{12\left(1-v^{2}\right)}
$$

which after substitution of Equations 1, 4 and 5 results in:

$$
D_{p}=\frac{1}{\rho^{3}}\left[((1-\alpha) \rho+\alpha)^{3}+\alpha^{3}\left(\rho^{2}-1\right)\right] \frac{E t_{i n i}{ }^{3}}{12\left(1-v^{2}\right)}
$$

Graphical representation of Equation 7 (Figure 3) shows that foaming (i.e., $\alpha$ ) between $30-90 \%$ of the initial solid sheet $\left(t_{i n i}\right)$ results not only in improved bending rigidity above the solid plate, but improved 
bending rigidity above foaming the entire plate ( $\alpha=1,1.0 t_{\text {ini }}$ foamed plate). Thus, foamed steel sandwich panels have the potential for greatly improved stiffness and local buckling stress under in-plane load.

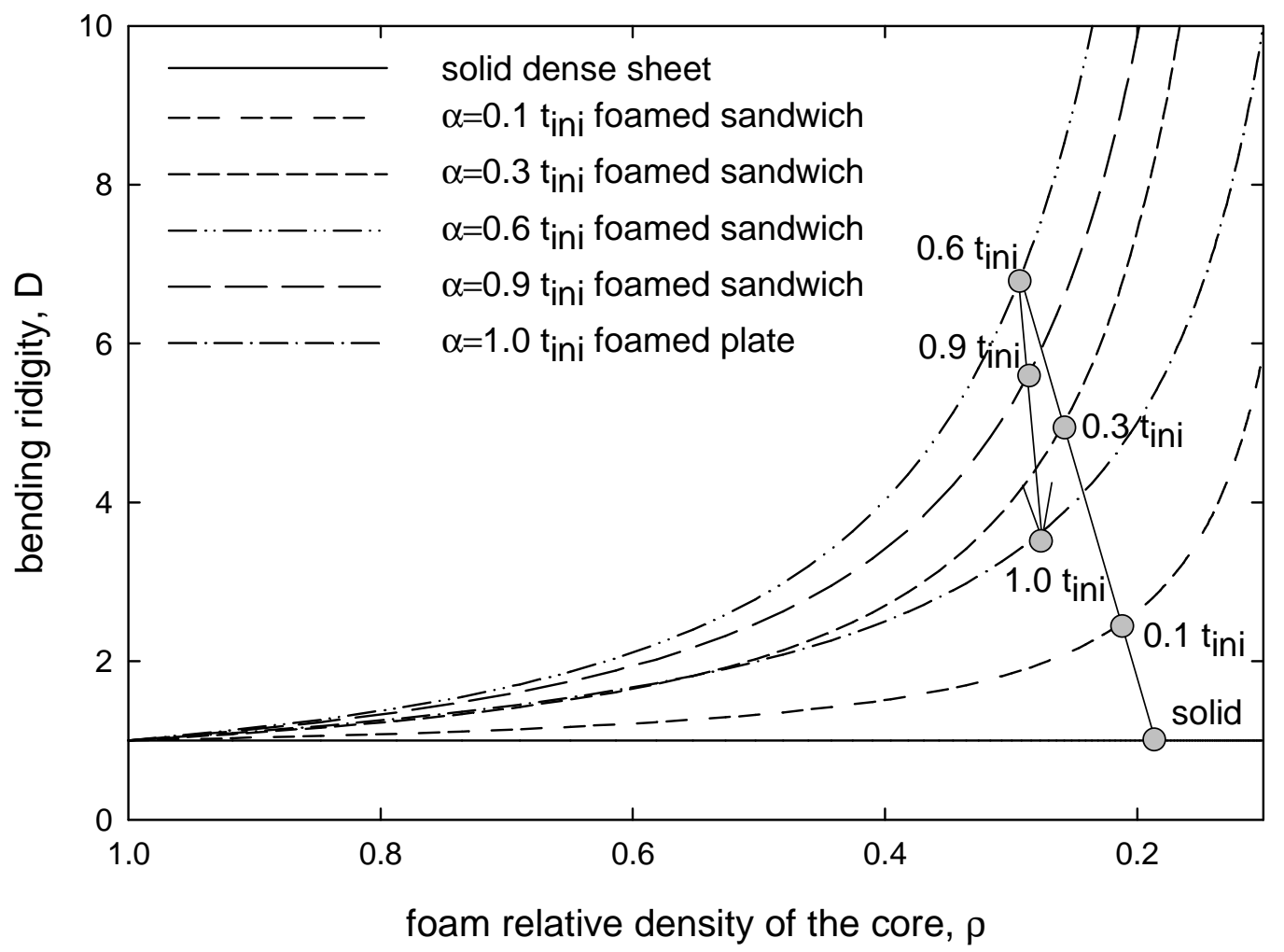

Figure 4. Increase in bending rigidity with panel foaming

\section{Local buckling of foamed steel sandwich panels}

For the foamed steel sandwich panel introduced in the previous section the in-plane elastic local plate buckling stress, $f_{c r}$, is proportional to the plate bending rigidity:

$$
f_{c r}=k \frac{\pi^{2} D_{p}}{b^{2}\left(t_{c}+2 t_{s}\right)}
$$

where $k$ is the plate buckling coefficient, $b$ is the plate width, and all other variables are previously defined. Thus, the improved plate bending rigidity (Equation 7) also provides plates with higher in-plane elastic local buckling stress. 
However, if $f_{c r}$ of Equation 8, utilizing Equation 7 for the plate bending rigidity is employed the predicted local buckling stress is often higher than the actual local buckling stress due to shear deformations in the low density core and lack of composite action between the core and face sheets resulting in local bending of the face sheets in isolation. This problem has seen significant study in the literature [14], [15], [16], [17], and [18]. In particular, Kardomates in [18] found that Allen's solutions of [14] were in best agreement with rigorous continuum mechanics solutions. Thus, Allen's approach has been adopted for further study here.

The approach of Allen, for incorporation of shear and face sheet bending, is to (a) simplify the bending rigidity, and (b) smear the rest of the effects into the plate buckling coefficient, $k$. The plate bending rigidity, $D_{p}$, is reduced (and simplified) by ignoring the stiffness of the core, i.e. $E_{f}$ of Equation 6 is set to zero, resulting in:

$$
D_{p}=\frac{E_{s} t_{s}\left(t_{c}+t_{s}\right)^{2}}{2\left(1-v_{s}^{2}\right)}
$$

For low density foam cores (e.g., $\rho=18 \%$ for the foam of Figure 1 ) and utilizing Equation 2 it is found the contribution of the foamed core to the plate bending rigidity is less than $1 \%$. Thus, the simpler expression of Equation 9 is justified even without considering shear deformations.

For a simply supported plate of length $a$, width $b$, uniformly compressed on the sides with width $b$, the plate buckling coefficient, $k$, of Allen, including shear deformation is as follows:

$$
k=\left(\frac{m b}{a}+\frac{n^{2} a}{m b}\right)^{2}\left\{\frac{1}{1+r\left(\frac{m^{2} b^{2}}{a^{2}}+n^{2}\right)}+\frac{t_{s}{ }^{2}}{3\left(t_{c}+t_{s}\right)^{2}}\right\}
$$

where the first term in the parentheses is the classic isotropic plate solution (and converges to $k=4$ as $a / b \rightarrow \infty), m$ is the number of transverse buckling half-waves, $n$ is the number of longitudinal (in the direction of loading) buckling half-waves, and $r$ accounts for shear deformation as given by: 


$$
r=\frac{\pi^{2}}{b^{2}} \frac{D_{p}}{G_{c}\left(t_{c}+t_{s}\right)^{2} / t_{c}}=\frac{\pi^{2}}{2\left(1-v_{c}^{2}\right)} \frac{E_{s}}{G_{c}} \frac{t_{s} t_{c}}{b^{2}}
$$

where $G_{c}$ is the shear modulus of the foam in the core. Note, if the core is isotropic unfoamed steel $r$ depends on $v$ and the ratio of $t_{s} t_{d} / b^{2}$, and for typical $b / t, r$ is less than 0.1. If the core is completely rigid in shear $r=0$.

As illustrated in Figure 5, in classic isotropic theory the minimum $k$ occur at $a / b=$ integer and converge to 4 as $a / b \rightarrow \infty$. However, for $k$ of Equation 10 the minima no longer occur at integer values and instead occur at $a / b=\chi_{\min }$ where $\chi_{\min }$ is a function of $r$ and $t_{s} /\left(t_{c}+t_{s}\right)$. Allen proposed that iteration be used, i.e. for a given $a / b$ iterate on $m$ and $n$ until the minimal $k$ is determined.

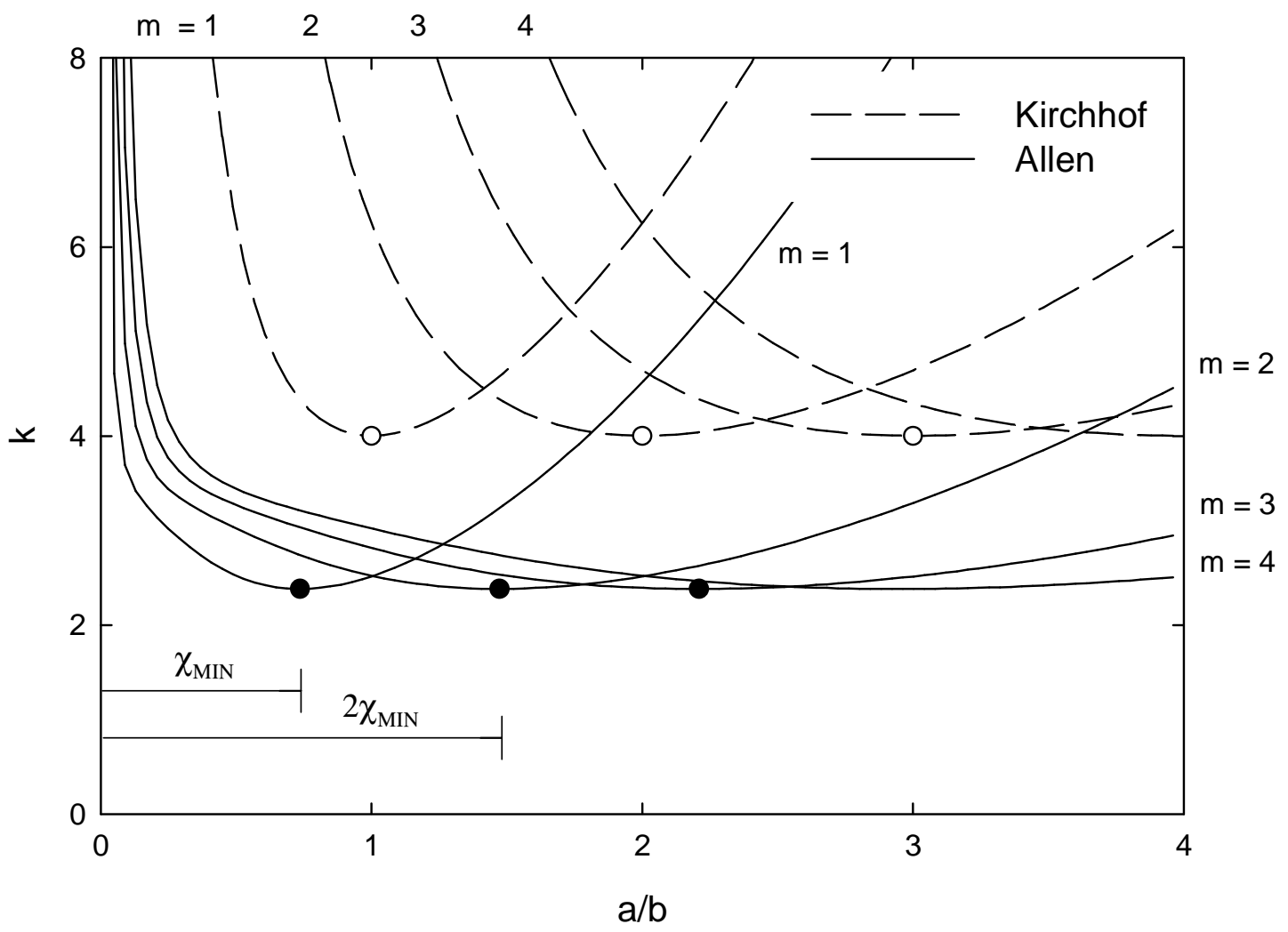

Figure 5. Plate buckling coefficient, $k$, as a function of plate aspect ratio $(a / b)$ comparing classical local buckling (Kirchoff) theory with the solution of Allen for $r=0.3$ and $t_{s} /\left(t_{c}+t_{s}\right)=0.1$ 
To expedite the use of Allen's solution a closed-form solution to the $a / b$ at which $k$ is a minimum is derived. First, noting $n=1$ always generates a minima, Equation 10 is simplified and re-written in a form more amenable to analytical manipulation:

$$
\begin{gathered}
k=\left(s+2+\frac{1}{s}\right)\left\{\frac{1}{1+r(s+1)}+\frac{1}{3} \xi^{2}\right\} \\
s=\left(\frac{m b}{a}\right)^{2}, \quad \xi=\frac{t_{s}}{t_{c}+t_{s}}
\end{gathered}
$$

Differentiation with respect to $s$ and setting to 0 to find the minima provides:

$$
\left(\frac{1}{s^{2}}-1\right)\left\{\frac{1}{1+r(s+1)}+\frac{1}{3} \xi^{2}\right\}+\frac{\left(s+2+\frac{1}{s}\right) r}{(r(s+1)+1)^{2}}=0
$$

Which has four solutions, however only one of the solutions is positive, thus:

$$
s_{\text {min }}=\frac{\frac{4}{9 r}+\frac{1}{9 r^{2}}+\frac{1}{\xi^{2} r}-\frac{1}{\xi^{2} r^{2}}+\frac{4}{9}}{\beta}+\beta-\frac{\xi^{2} r^{2}+2 \xi^{2} r}{3 \xi^{2} r^{2}}
$$

The auxiliary variables employed to simplify the expression for $s_{\min }$ are:

$$
\begin{gathered}
\beta=\left(\sqrt{\alpha_{1}}+\alpha_{2}\right)^{\frac{1}{3}} \\
\alpha_{1}=\frac{8 / 9}{\xi^{2} r^{2}}+\frac{20 / 9}{\xi^{2} r^{3}}+\frac{2}{\xi^{2} r^{4}}-\frac{1 / 3}{\xi^{4} r^{2}}+\frac{7 / 9}{\xi^{2} r^{5}}+\frac{10 / 3}{\xi^{4} r^{3}}+\frac{1 / 9}{\xi^{2} r^{6}}+\frac{4}{\xi^{4} r^{4}}+\frac{4 / 3}{\xi^{4} r^{5}}-\frac{1}{\xi^{6} r^{3}}+\frac{2 / 3}{\xi^{4} r^{6}} \\
+\frac{3}{\xi^{6} r^{4}}-\frac{3}{\xi^{6} r^{5}}+\frac{1}{\xi^{6} r^{6}} \\
\alpha_{2}=\frac{4}{9 r}+\frac{2}{9 r^{2}}+\frac{1}{27 r^{3}}+\frac{1}{\xi^{2} r}+\frac{1}{\xi^{2} r^{2}}+\frac{1}{\xi^{2}+r^{3}}+\frac{4}{27}
\end{gathered}
$$

From the preceding the aspect ratio at which a given number of half-waves, $m$, reaches a minimum is:

$$
\left(\frac{a}{b}\right)_{\text {min }}=\chi_{\min } m=\sqrt{1 / s_{\min }} m
$$

$\chi_{\min }=\sqrt{1 / s_{\min }}$ can also be estimated from Figure 6 for known $r$ and $\xi$. 


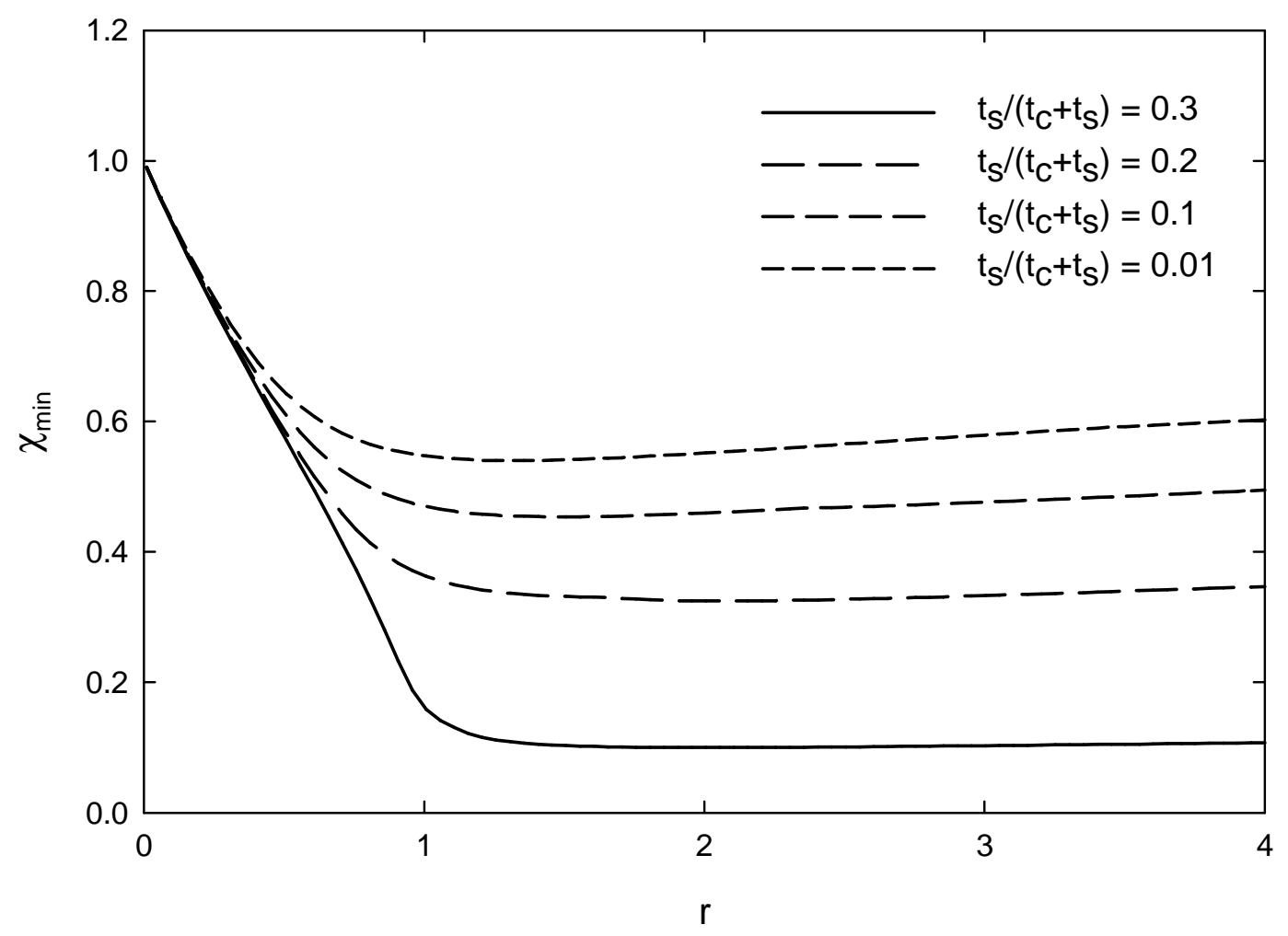

Figure 6. Graphical representation of closed-form solution for $\chi_{\min }$

The overall potential impact of shear deformation and non-composite face sheet bending on the local buckling solution is illustrated in Figure 7. As shear deformations increase, i.e. as $r$ increases, the plate buckling coefficient decreases. The local plate bending (captured in the ratio of the face sheet thickness to the sum of face sheet and core thickness, $\left.t_{s} /\left(t_{c}+t_{s}\right)\right)$ also influences the solution, but to a far lesser extent. Note, as $a / b \rightarrow 0$ the inclusion of shear deformation, $r$, in Equation 10 causes $k$ to converge to a finite value instead of infinity, as in the case of an isotropic plate. 


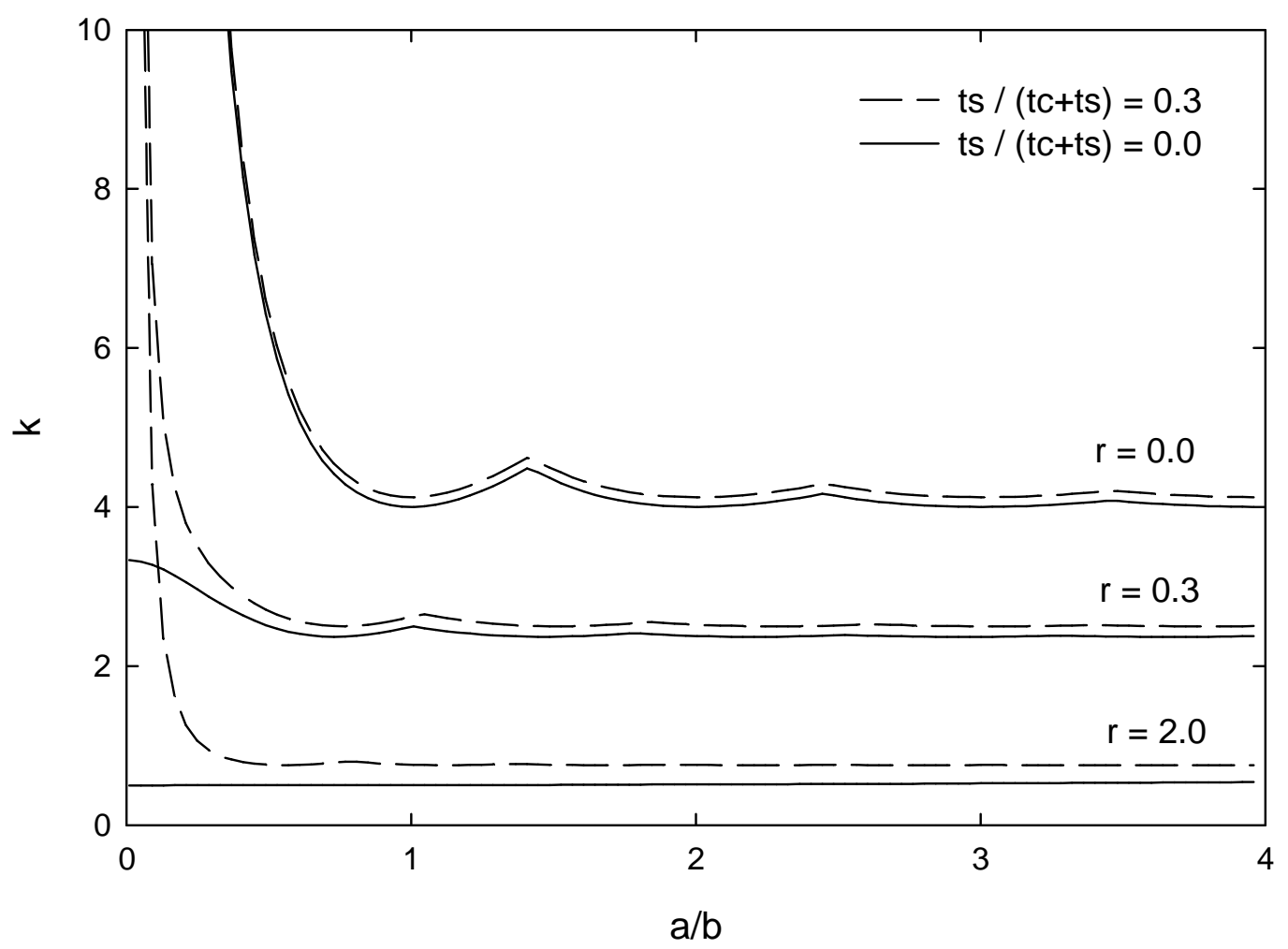

Figure 7. Plate buckling coefficient, $k$, as a function of plate aspect ratio $(a / b)$ demonstrating the impact of shear deformation $(r)$ and face sheeting bending $t_{s} /\left(t_{c}+t_{s}\right)$ on the solution

\section{$4 \quad$ Computational modeling of steel foam sandwich panels}

To further explore the predicted behavior for steel foam sandwich panels and provide predictions of the ultimate strength of in-plane loaded steel foam sandwich panels a series of finite element models was constructed. The models were completed in LS-DYNA [24]. Brick elements $(500,000$ to $1,000,000$ type 164 solids [24]) were used throughout: 150 to 200 transverse elements, and six elements through the thickness, as shown in Figure 8a were typical, but element aspect ratios were maintained from 1 for $b / t=50$, up to 2 for $b / t=200$. Thin steel plates $(0.3 \mathrm{~mm})$ along the panel perimeter were employed to eliminate the sharp load application to the continuum representation (Figure 8a). The steel face sheets were modeled with a standard J-2 plasticity formulation and isotropic hardening. The steel properties: $E_{s}=203000 \mathrm{MPa}, f_{y}=385 \mathrm{MPa}$, and complete strain hardening regime 
were obtained from coupon tests [25] of steel sheet. In addition, tensile failure in the face sheet was simulated via element deletion at an accumulated plastic strain of $18 \%$.

Modeling the steel foam core requires a more sophisticated approach than standard J-2 plasticity. Steel foam is still compressible after its yield and in the plastic regime $v$ is typically less than 0.3 , as opposed to solid steel, which is practically incompressible and thus $v=0.5$. For steel foam, the yield and subsequent plastic surface evolution depend not only on deviatoric stress invariant $J_{2}$ but also on the trace of the stress tensor $I_{1}$. Miller et al. [26], and later Deshpande and Fleck (D-F) [27] introduced a generalized von Mises-Huber plasticity, which accounts for pressure dependence. Reyes [28] and Hansen et al. [29] enhanced D-F plasticity with tensile fracture criteria based on the major principal stress and D-F plasticity with the fracture criteria is implemented in LS-DYNA [24]. The D-F formulation must be calibrated against a uniaxial material test, and the low density hollow sphere foam of Figure 1 as tested and reported in Figure 3 is used for that purpose here.

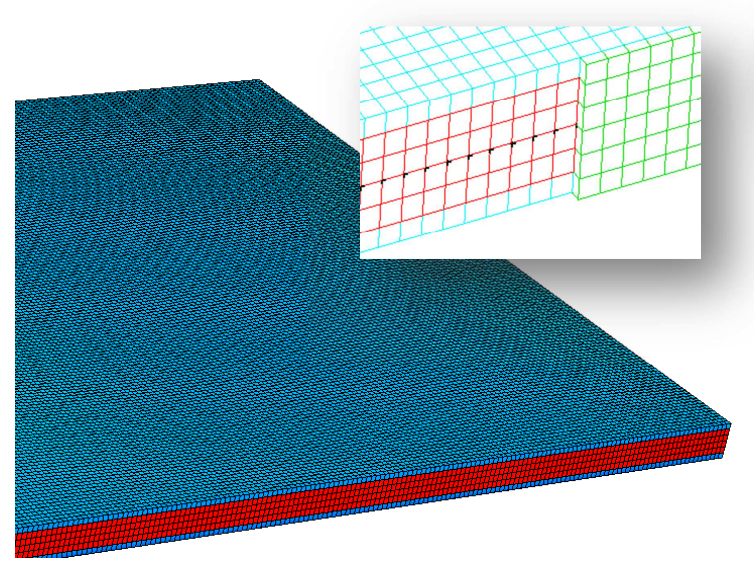

(a) typical mesh, inset provides details of simply supported boundary condition implementation

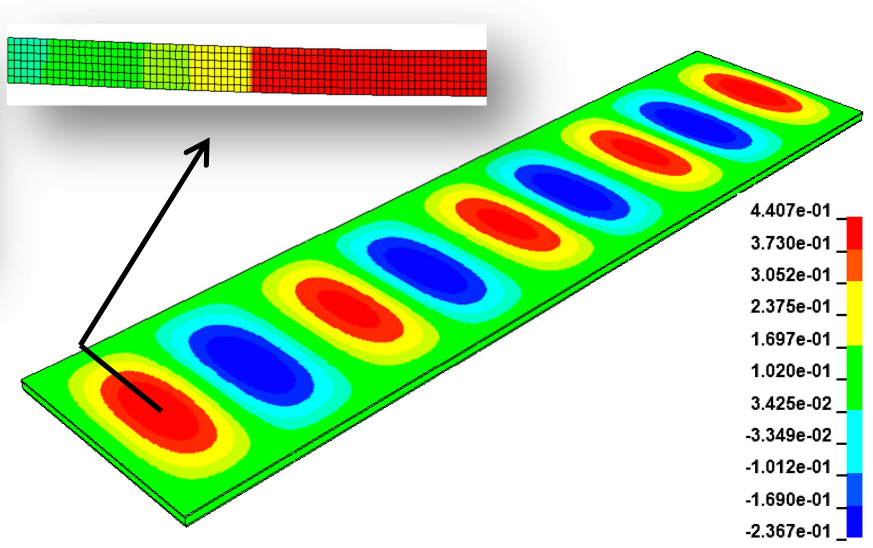

(b) typical buckling mode for a shear deformable core $(r=1.45)$, inset highlights shear deformation $(\mathrm{mm})$

Figure 8. Finite element model of a simply supported steel foam sandwich panel plate (steel face sheet and steel foam core are modeled with brick elements in LS-DYNA) under in-plane compression

A simple demonstration of the efficacy of the developed model is summarized in Figure 9, where the model has been exercised with a central out-of-plane pressure load. In Figure 9, assuming $30 \%$ of the initial thickness $(\alpha=0.3)$ is foamed, the resulting plate rigidity is plotted against the relative density of 
the foamed core. Young modulus of the foamed core was for obtained from Equation 2. The foam at a relative density of $20 \%$ and the resulting rigidity is just below that of Kirchhoff thin plate theory (i.e., Equation 7). For lower density the deviation from thin plate theory is even greater. The results demonstrate that the developed finite element model can account for shear deformations, and bending in the face sheets.

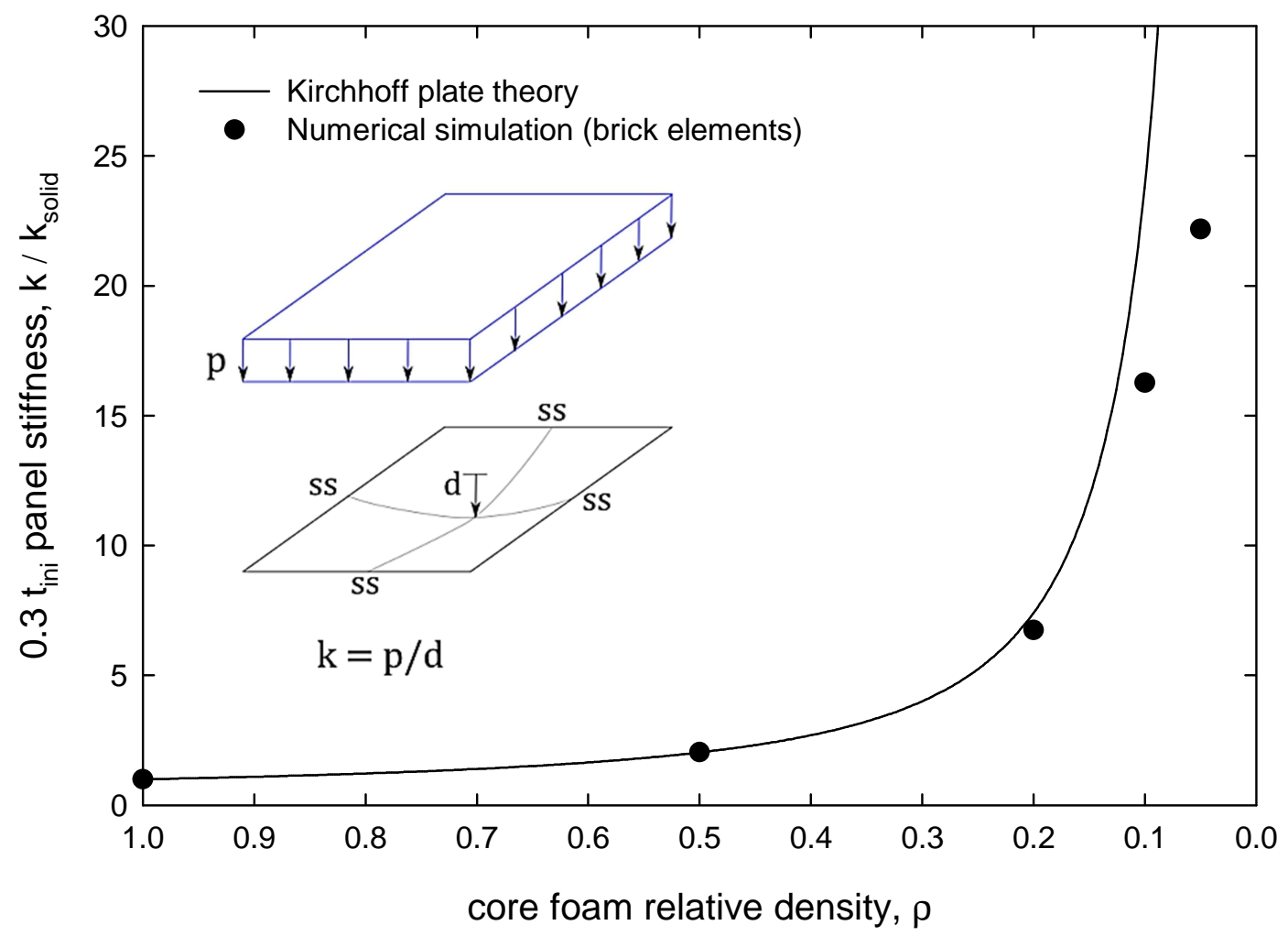

Figure 9. Effect of core foaming on bending rigidity of sandwich panels

$200 \times 200 \mathrm{~mm}$ panel. $\alpha=0.3$ of $t_{\text {ini }}=2 \mathrm{~mm}$ mild steel dense sheet foamed from $\rho=1.0 \sim 0.05$.

Eigenbuckling analysis, Figure $8 \mathrm{~b}$, was performed on the developed finite element model to explore the accuracy of Allen's elastic buckling solution (Equations 8-10). For the eigenbuckling models, based on a $t_{i n i}=1 \mathrm{~mm}, 30 \%$ of the solid sheet was foamed to $18 \%$ relative density (i.e. the foam of Figure 1) resulting in $t_{s}=0.35 \mathrm{~mm}$ and $t_{c}=1.67 \mathrm{~mm}$. Panel width $b$ was varied from 50 to 200 to explore a wide range of $b / t$ ratios. Figure 10 shows that Allen's elastic buckling solution works well for steel foam sandwich panels over a large variation in $b / t$ ratios (and shear deformation ratio, $r$ ). 


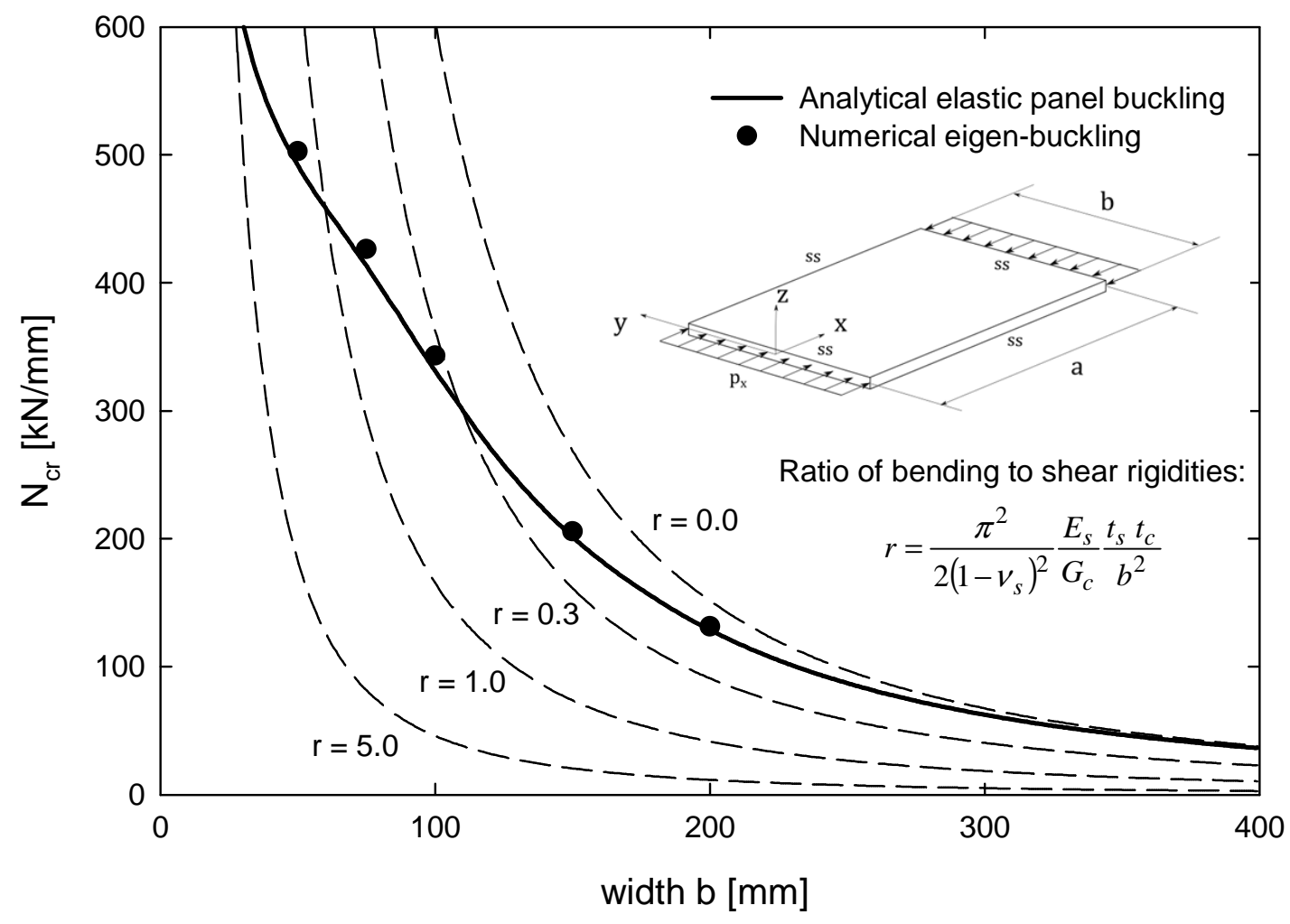

Figure 10. Comparison of Allen's elastic buckling solution with numerical plate buckling model (dashed lines provide a means to understand the impact of shear deformation on solution)

\section{$5 \quad$ Strength of in-plane loaded sandwich panels}

Prediction of the compressive strength of a steel foam sandwich panel loaded in-plane is the ultimate goal of the work presented herein. In this section Winter's effective width approximation is modified for steel foam sandwich panels and then compared against nonlinear collapse simulations in LS-DYNA.

\subsection{Squash load and equivalent yield stress}

The squash load is the compressive load at which the section is fully yielded. In the case of steel foam sandwich panels this is modified to the compressive load at which the steel face sheets are fully yielded. The equivalent yield stress for the sandwich panel, $f_{y p}$, may then be found from simple force balance: 


$$
f_{y p}=\frac{2 t_{s} f_{y s}+t_{c} \cdot \min \left(f_{y c}, E_{c} \frac{f_{y s}}{E_{s}}\right)}{2 t_{s}+t_{c}}
$$

where the yield stress of the face sheets, $f_{y}$, is explicitly denoted here as $f_{y s}$, and the yield stress and modulus in the foamed core are denoted as $f_{y c}$ and $E_{c}$. Typically, the core is still elastic when the face sheets yield, thus the second term of the minimum in Equation 20 usually controls. Alternatively $f_{y p}$ may be expressed explicitly in terms of the foaming parameters $\alpha$ and $\rho$ :

$$
f_{y p}=\frac{(1-\alpha) f_{y s}+\alpha \frac{1}{\rho} \cdot \min \left(f_{y c}, E_{c} \frac{f_{y f}}{E_{s}}\right)}{(1-\alpha)+\frac{\alpha}{\rho}}
$$

Also note, per [2]: $f_{y c} \propto f_{y s} \rho^{1.5}$, and this approximation combined with Equation 2: $E_{c} \propto E_{s} \rho^{2}$ may be used to provide an approximate expression for $f_{y p}$ that is only dependent on the foaming parameters.

\subsection{Winter's design method}

For thin solid steel plates the most widely accepted engineering approach to predicting their in-plane compressive strength is Winter's effective width approach [1] or some variant thereof. Winter's approach (see [19] for a full summary) is predicated on the early test observations of [20] and the semiempirical derivation of von Karman in [21]. Winter conducted his own tests in [1] which lead to empirical corrections to von Karman's work to account for imperfections. Ultimately, modern specifications [23] have led to further small modifications. As implemented [23], Winter's approach provides the reduced width of the plate, $b_{e}$, that is effective in carrying the maximum stress, $f_{y}$, per:

$$
b_{e}=\left\{\begin{array}{cl}
b & \text { if } f_{c r} \geq 2.2 f_{y} \\
b\left(1-0.22 \sqrt{\frac{f_{c r}}{f_{y}}}\right) \sqrt{\frac{f_{c r}}{f_{y}}} & \text { if } f_{c r}<2.2 f_{y}
\end{array}\right.
$$

where $b$ is the plate width, $f_{c r}$ is the local plate buckling stress, and $f_{y}$ is the plate material yield stress. The method results in a predicted compressive strength, $P_{n}$, for the plate of

$$
P_{n}=b_{e} t f_{y}
$$


Here we explore the generalization of this design approach where $f_{y}$ is replaced with $f_{y p}$ of Equation 20 and $f_{c r}$ includes Allen's reductions for shear deformation and face sheet bending: Equations 8,9 and 10 as well as utilize the closed-form expression of Equation 18 to determine the minimum $f_{c r}$ for a given plate.

\subsection{Sandwich panel collapse simulations and comparisons}

The LS-DYNA brick element model, employing J-2 plasticity for the face sheets and the triaxial stress dependent D-F model for the foamed steel core as described in Section 4, is employed here to conduct material and geometric nonlinear collapse analysis of simply supported steel foam sandwich panels loaded under in-plane compression. Geometric imperfections in the shape of the first eigenmode with magnitudes of $0.1 t$ and $0.34 t$ (see [22]) where $t$ is the total thickness, were employed. As in the eigenbuckling analysis of Section 4: $t_{i n i}=1 \mathrm{~mm}, \alpha=30 \%, \rho=18 \%$ (i.e. the foam of Figure 1 ) which results in $t_{s}=0.35 \mathrm{~mm}$ and $t_{c}=1.67 \mathrm{~mm}$. Panel width $b$ was varied from 50 to 200 .

The force at collapse in the models (normalized by the solid sheet squash load $P_{y}=b t_{\text {ini }} f_{y s}$ ) is provided as a function of the panel width-to-thickness ratio in Figure 11. The figure also provides the strength prediction based on Winter's method, Equation 22. Three curves are provided for Winter's method: solid steel (unfoamed) sheet; sandwich panel - ignoring shear effects, and; sandwich panel - including shear effects. The results indicate that shear effects must be included in the solution, but if they are included (and the yield stress suitably modified to $f_{y p}$ ) Winter's method provides an accurate prediction of strength. Further, even granting the small loss in capacity due to shear deformations, the foamed panel outperforms the solid steel sheet for a large range of $b / t$ ratios. 


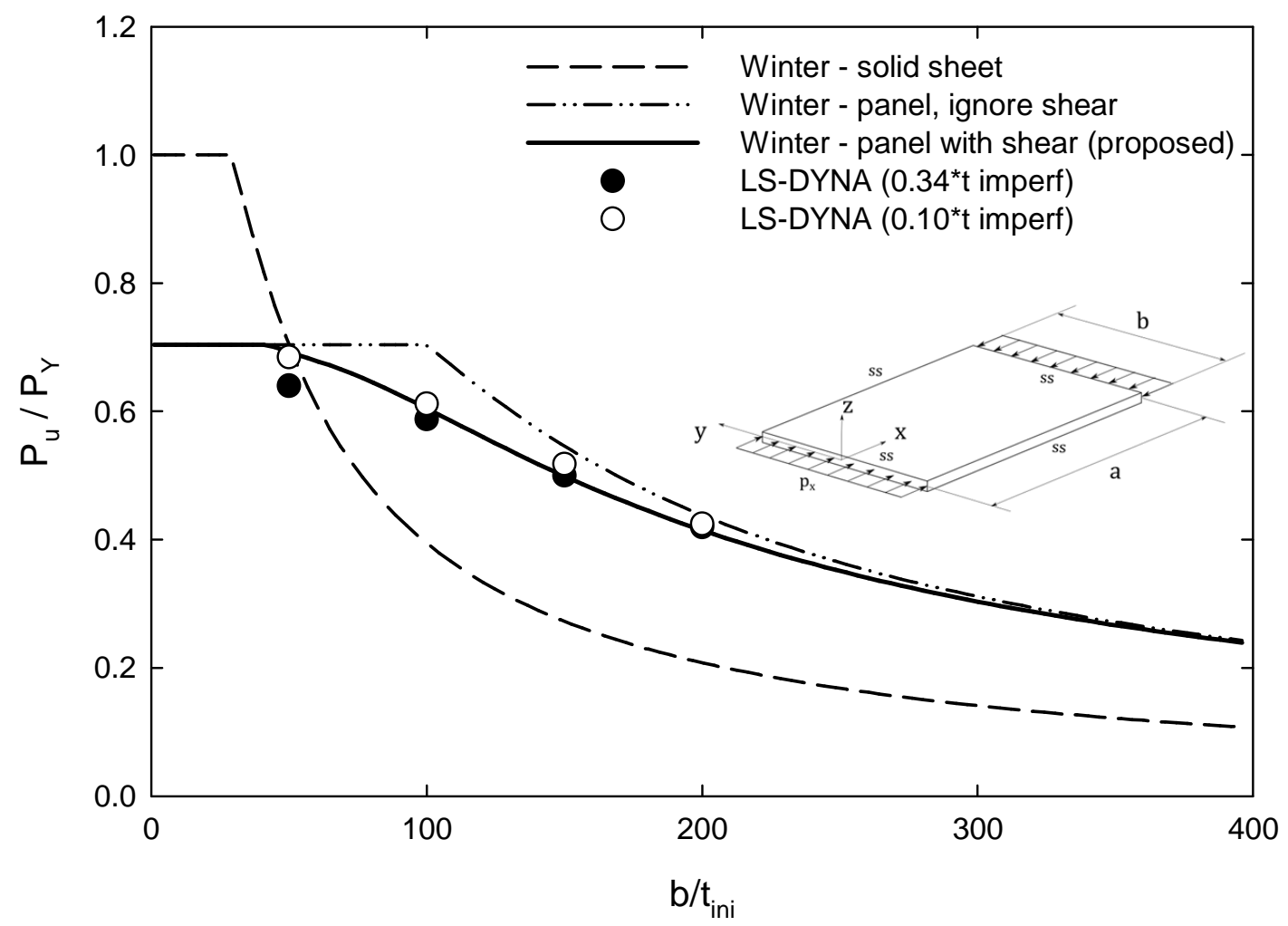

Figure 11. Comparison of finite element collapse simulations of steel foam sandwich panels with predicted strength based on modified version of Winter's method.

The collapse simulations also provide further insight into how the sandwich panel carries load, and to a limited extent an explanation as to why Winter's method continues to work in this case. Consider the $b / t_{i n i}=50$ model at peak strength; the longitudinal stress contours are provided in Figure 12 . The variation in stress along the length, in the face sheets, increases and decreases (though in net compression) as it follows the buckling waves. The stress at the center, in the foamed steel, is essentially zero. This is in stark contrast to a solid steel sheet, which has high net compression in the center. This can all be observed in greater detail for a transverse cut of the longitudinal stress: consider the section called out in Figure 12 and provided in Figure 13b. If the longitudinal stress at the same section is integrated through the thickness, then divided by the total thickness $\left(t_{c}+2 t_{s}\right)$ to provide an equivalent stress, the result is Figure 13a. The distribution of Figure 13a is readily recognized as similar to the classic 
stress distribution that motivated the effective width expressions of von Karman and later Winter. Interestingly, as shown in the figure, the maximum stress at failure is approximately $f_{y p}$ (i.e. $117 \mathrm{MPa}$ ).

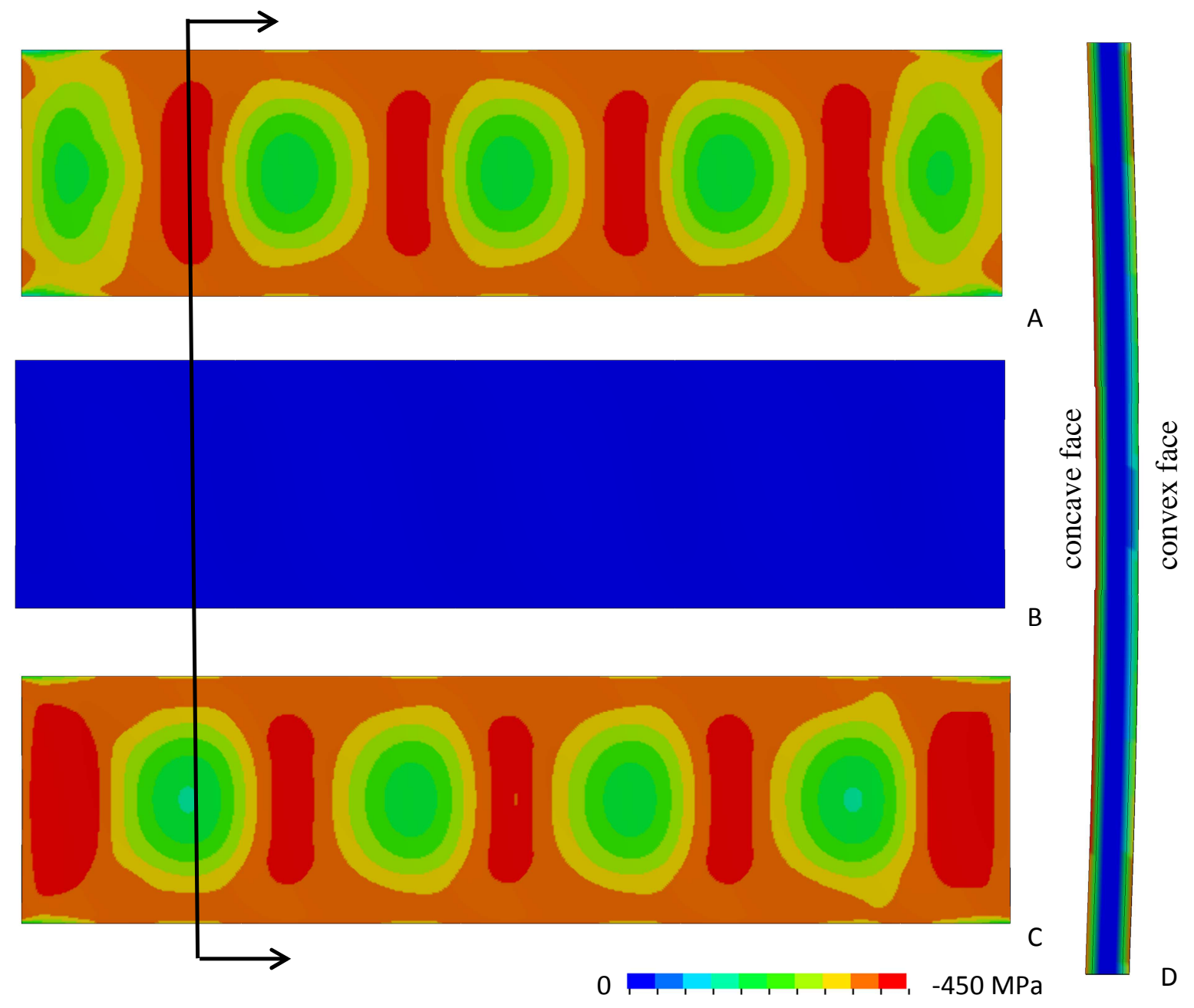

Figure 12. In-plane stress distribution in a panel: A. top face (steel plate), B. mid-plane (foam plate), C. top face (steel plate), D. cross-section (top steel - steel foam - bottom steel face) 

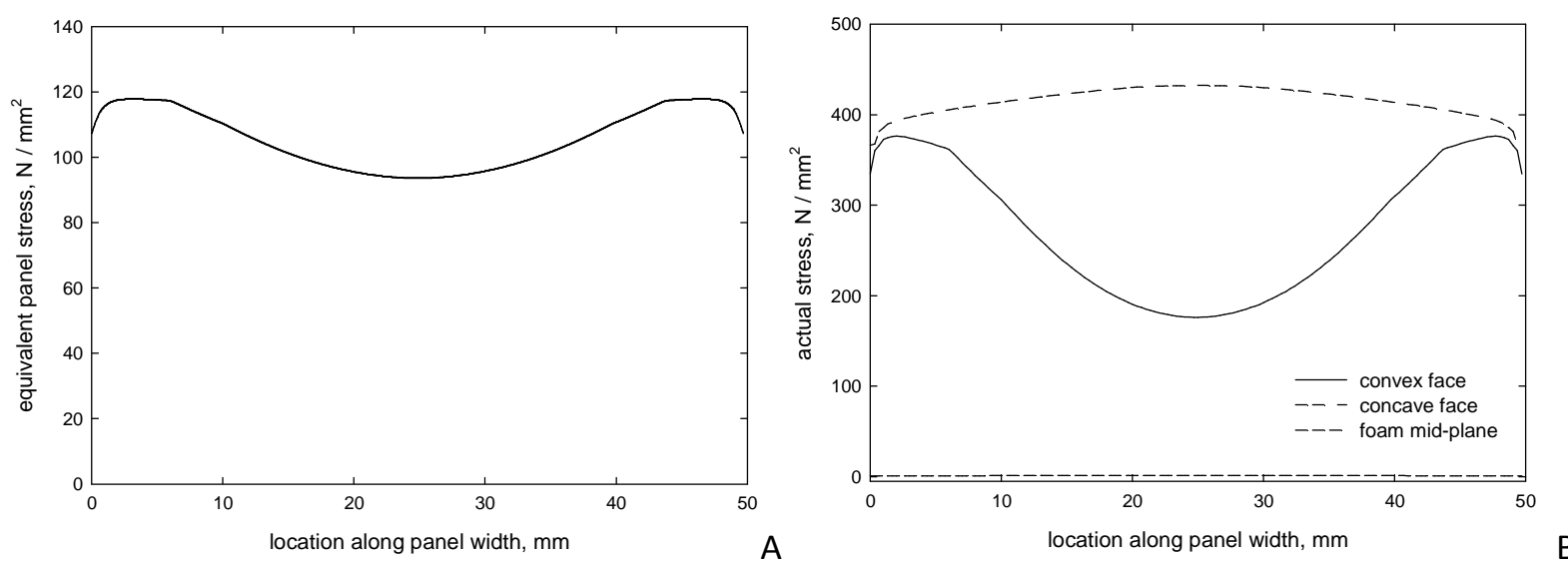

Figure 13. Resistance mechanism of sandwich panels: A. integral through the thickness (effective compressive resistance) expressed in terms of the equivalent smeared stress, B. stress distribution in: convex steel face, concave steel face and foam mid-plane.

\section{Steel foam sandwich panel optimization}

To illustrate the performance that is possible with steel foam sandwich panels the strength predicted by the suitably modified and validated Winter's method (Equation 22) is compared to a solid plate (thickness $=t_{\text {ini }}$ ) of the same weight for a variety of different foamed depths. The commercially available steel foam of Figure $1(\rho=18 \%)$ is again used for the core density, and the depth of foaming, $\alpha$, is varied from 0.1 to 0.6 (i.e. the initial portion of the plate that is foamed varies from $0.1 t_{i n \mathrm{i}}$ to $0.6 t_{i n i}$ ). The plate width is varied and the resulting strength prediction is provided in Figure 14.

Fundamentally, foaming decreases $f_{y}$ (to $f_{y p}$ via Equation 20) and increases the local buckling stress $f_{c r}$ (through an enhanced plate rigidity appropriately reduced for shear deformations and face bending Equations 8,9,10). Thus, as shown in Figure 14a for stocky plates (low $\left.b / t_{i n i}\right)$ the sandwich panel has a reduced capacity when compared to a solid plate of the same weight, but as slenderness increases the sandwich panel capacity exceeds that of the solid plate. In striking the balance between reduced $f_{y}$ and enhanced $f_{c r}$ it is shown that a foamed depth of $0.3 t_{\text {ini }}(\alpha=0.3)$ provides the biggest improvements over the solid plate, over the widest range of $b / t_{\text {ini }}$, Figure $14 \mathrm{~b}$. In the studied case strength gains above the solid plate between $150 \%$ and $200 \%$ are realized for $b / t_{i n}>100$. 


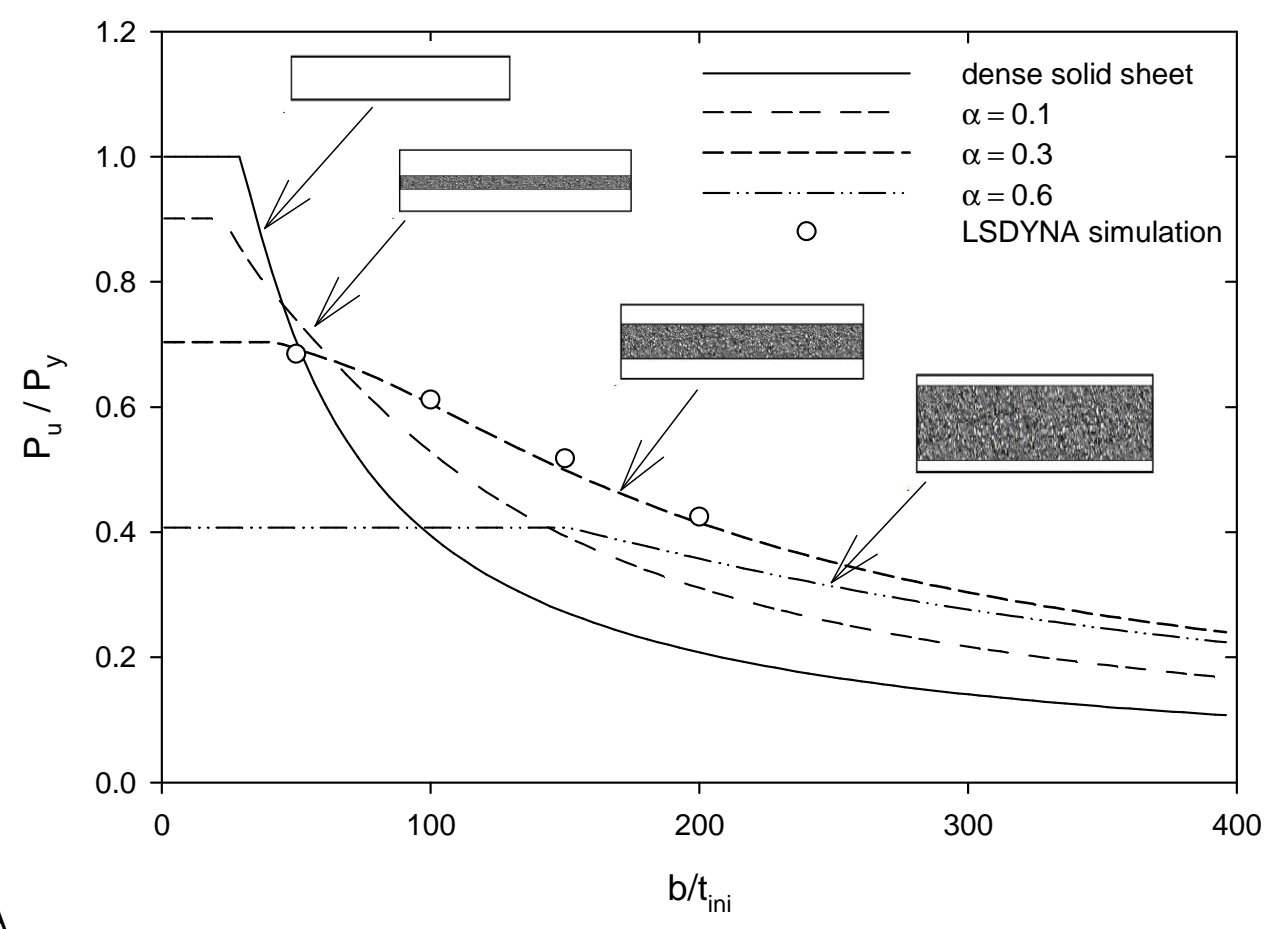

A

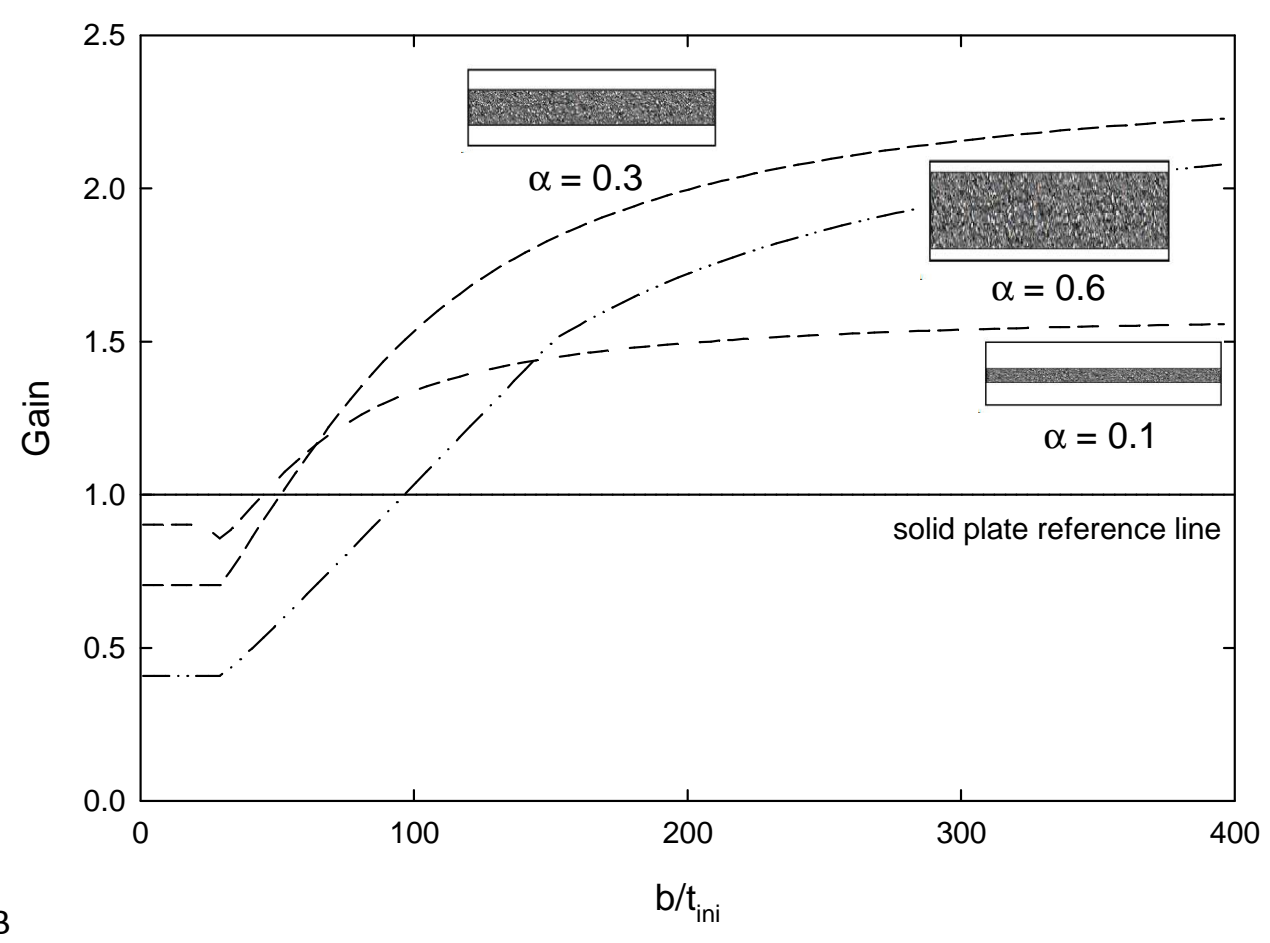

Figure 14. Strength of solid steel and sandwich panels of the same weight, $\rho=18 \%$ in the foam cores and depth of foaming varied, (a) strength normalized to yield as a function of initial plate width-to-thickness, (b) strength normalized to solid plate strength as a function of initial plate width-to-thickness 


\section{Discussion}

This work provides a basic building block in the development of steel foams for structural engineering. Strength predictions of steel in in-plane compression, and appropriate reductions for local buckling, are fundamental to the creation of thin-walled members comprised of steel foam. It is somewhat remarkable that Winter's equation once again can be utilized to predict capacity. It is worth noting that the final form of Winter's expression and its modifications should be based on tests, not just the simulations provided here; however, the work here provides confidence that the basic approach can be realized, though additional calibration will no doubt be required.

This study elucidates the potential stiffness and strength gains of steel foam sandwich panels, but does not explore energy absorption and ductility. Even for the cases where the squash load is reduced (i.e. the "Gain" in Figure $14 \mathrm{~b}$ is $<1.0$ ) the compressive deformation capacity in these sandwich panels will be greatly increased. Design procedures for prediction of the deformation capacity (and thus ductility and energy dissipation) are a logical next step for this work. Significant effort remains at all levels to develop steel foam as a structural material; nonetheless, work such as that provided herein is intended to aid and encourage that development.

\section{Conclusions}

Steel foam is emerging as a new structural material with intriguing properties: high stiffness-to-weight ratio, high energy absorption, and other advantages. Foaming steel increases bending rigidity, but decreases the effective modulus and yield stress. A steel foam sandwich panel, consisting of solid steel faces and an interior of foamed steel further increases the bending rigidity, and limits the loss in effective modulus and yield stress. However, depending on the density of the foamed steel core, shear deformations and non-composite bending of the face sheets, must be accounted for in the behavior of steel foam sandwich panels. It is found that the approximation of Allen [14] effectively captures these 
phenomena in the prediction of the elastic local buckling stress for a steel foam sandwich panel. This observation is verified, by detailed continuum finite element models of a steel foam sandwich panel with brick elements. Allen's elastic local buckling prediction is extended and a closed-formed solution provided. The ultimate strength of steel foam sandwich panels is explored with the detailed finite element model and it is found that Winter's classic effective width method suitably modified for the effective yield stress (derivations provided herein) and local buckling stress (based on Allen's method) is an excellent predictor of steel foam sandwich panels over a wide slenderness range. Further, exploration of the developed expressions utilizing one commercially available steel foam demonstrates that foaming the middle $30 \%$ of a solid steel plate leads to optimal strength gains, which can be in excess of $200 \%$ of the strength of the solid steel sheet of the same mass. Significant work and experimental validation remain, but the work presented herein shows that a basic buckling block of thinwalled member design: Winter's effective width method, can be suitably modified for steel foam sandwich panels.

\section{Acknowledgments}

This paper is based in part upon work supported by the U.S. National Science Foundation under Grants CMMI-1000334, CMMI-1000167, CMMI-0970059 and TG-MSS110026. Any opinions, findings, and conclusions or recommendations expressed in this material are those of the author(s) and do not necessarily reflect the views of the National Science Foundation. This work used the Extreme Science and Engineering Discovery Environment (XSEDE), which is supported by National Science Foundation grant number OCl-1053575.

Dr. Bahnart and Wiley- $\mathrm{VCH}$ are gratefully appreciated for their permission to reproduce figures of sandwich panels (Figure 2). The figure was originally published in Advanced Engineering Materials: 
Banhart J., Seeliger H., Aluminum foam sandwich panels: manufacture, metallurgy and applications, 2008; 10:793-802. Copyright Wiley-VCH Verlag GmbH \& Co. KGaA. Reproduced with permission.

The authors are grateful to Dr. Zhanjie Li for his insights on numerical modeling of simply supported plates with brick continuum elements. The assistance of Mahmoud Alloush in preparing the figures is appreciated. The authors also wish to thank Drs. Hartmut Goehler and Guenter Stephani of the Fraunhofer Institute for preparing the hollow sphere foams.

\section{References}

[1] Winter G. Strength of thin steel compression flanges. Engineering Experiment Station bulletin, no. 35, pt. 3. Ithaca, N.Y. : Cornell University, 1947. Reprint from: Transactions of American Society of Civil Engineers Vol. 112, with an appendix not contained in the original publication.

[2] Ashby MF, Evans T, Fleck NA, Gibson NA, Hutchinson JW, Wadley HNG. Metal Foams: A Design Guide, Butterworth-Heinemann, 2000.

[3] Banhart J, Seeliger H. Aluminum foam sandwich panels: manufacture, metallurgy and applications. Advanced Engineering Materials 2008;10:793-802.

[4] Lefebvre LP, Banhart J, Dunand DC. Porous Metals and Metallic Foams: Current Status and Recent Developments. Advanced Engineering Materials 2008;10:775-787.

[5] Cardoso E, Oliveira BF, Study of the use of metallic foam in a vehicle for an energy-economy racing circuit. Materialwissenschaft Und Werkstofftechnik 2010;41;257-264.

[6] Bao HQ, Han BK, Transmission loss of metallic foams for the local resonance, in: 3rd International Conference on Bioinformatics and Biomedical Engineering, iCBBE, 2009.

[7] Kremer K, Liszkiewicz A and Adkins J. Development of Steel Foam Materials and Structures, US DOE and AISI final report DE-FC36-97ID13554, Fraunhofer USA - Delaware Center for Manufacturing and Advanced Materials, Newark, DE, 2004.

[8] Hipke T, Fraunhofer Institute, Chemnitz, Germany, personal communication, 2011. 
[9] Neugebauer R, Hipke T, Hohlfeld J, and Thümmler R. Metal foam as a combination of lightweight engineering and damping. Cellular Metals and Polymers. Singer RF, Koerner C, Alstaedt V, Muenstedt H (eds.) 2004:13-18.

[10] Coquard R, Rochais D, Baillis D. Conductive and Radiative Heat Transfer in Ceramic and Metal Foams at Fire Temperatures - Contribution to the Special Issue "Materials in Fire" Guest Editor K. Ghazi Wakili, July 2010.

[11] Lu T, Chen C. Thermal transport and fire retardance properties of cellular aluminium alloys, Acta Materialia 1999;47:1469-1485.

[12] Losito O, Barletta D, Dimiccoli V. A wide-frequency model of metal foam for shielding applications. IEEE Transactions on Electromagnetic Compatibility 2010;52:75-81.

[13] Xu S, Bourham M, Rabiei A. A novel ultra-light structure for radiation shielding. Materials and Design 2010;31:2140-2146.

[14] Allen HG. Analysis and Design of Structural Sandwich Panels, Pergamon, Oxford, 1969.

[15] Plantema JF. Sandwich Construction, John Wiley and Sons, New York, 1966.

[16] Vinson JR. The Behavior of Sandwich Structures of Isotropic and Composite Materials, Technomic, Lancaster, PA, 1999.

[17] Hohe J, Librescu L. Advances in the Structural Modeling of Elastic Sandwich Panels. Mechanics of Advanced Materials and Structures 2004;11:395-424.

[18] Kardomateas GA. An elasticity solution for the global buckling of sandwich beams/wide panels with orthotropic phases, Journal of Applied Mechanics, Transactions ASME 2010;77:1-7.

[19] Ziemian RD. Guide to Stability Design Criteria for Metal Structures, Chapter 4, 6th ed., Wiley, 2010.

[20] Schuman L, and Back G. Strength of Rectangular Flat Plates under Edge Compression, NACA Tech. Rep. No. 356, 1930.

[21] von Kármán T, Sechler EE, Donnell LH. Strength of Thin Plates in Compression, Trans. A.S.M.E., 1932; Vol.54,No.APM-54-5,pp.53-57. 
[22] Schafer BW, Grigoriu M, Peköz T. A probabilistic examination of the ultimate strength of coldformed steel elements, Thin-Walled Structures, 1998;31:271-288.

[23] American Iron and Steel Institute. Cold-formed steel design manual : specification for the design of cold-form steel structural members, New York, 2007.

[24] Hallquist J. LS-DYNA: theory manual, Livermore, California: Lawrence Software Technology Corporation, 2006.

[25] Vieira LCM Jr, Shifferaw Y, Schafer BW. Experiments on sheathed cold-formed steel studs in compression, Journal of Constructional Steel Research 2011;67:1554-1566.

[26] Miller RE. A continuum plasticity model for the constitutive and indentation behaviour of foamed metals, International Journal of Mechanical Sciences 2000;42:729-754.

[27] Deshpande V, Fleck NA. Isotropic constitutive models for metallic foams, Journal of the Mechanics and Physics of Solids 2000; 48:1253-1283.

[28] Reyes A. Constitutive modeling of aluminum foam including fracture and statistical variation of density, European Journal of Mechanics A/Solids 2003;22:815-835.

[29] Hanssen A, Hopperstad O, Langseth M, Ilstad H. Validation of constitutive models applicable to aluminium foams, International Journal of Mechanical Sciences 2002;44:359-406. 